\title{
Parental investment can moderate the negative effects of low socioeconomic status on children's health: an analysis of Kenyan national data
}

\author{
Vanessa Mbuma ${ }^{1}$, Lauren Lissner ${ }^{1}$, Monica Hunsberger ${ }^{1}$ (1) 8 \\ ${ }^{1}$ School of Public Health \& Community Medicine, Institute of Medicine, Sahlgrenska Academy, University of Gothenburg \\ Keywords: maternal education, parental investment, childhood stunting, Kenya \\ https://doi.org/10.29392/001c.29462
}

\section{Journal of Global Health Reports}

Vol. 5, 2021

\begin{abstract}
Background
Stunting is an indicator for cumulative growth deficits and long-term undernutrition. Determinants of stunting include poverty, food insecurity, poor sanitation, and low maternal education. Stunting has both short and long-term detrimental health and developmental effects on children. In 2020, around 149 million children under five were stunted worldwide. This study examines whether parental investment moderates the association between maternal education and childhood stunting in Kenya.
\end{abstract}

\section{Methods}

The 2014 Kenya Demographic and Health Survey was used to examine the variation in childhood stunting, analysed using binary logistic regression. Subgroup effect modification models were utilized to incorporate the interactions between maternal education and parental investments: marital status, household size, number of antenatal visits and breastfeeding duration on childhood stunting.

\section{Results}

This analysis included 17247 children under 5 years. The results indicated that $26 \%$ of Kenyan children under five were stunted in 2014. The prevalence of stunting was greater among males (30\%) than females (22\%). There was an increasing adverse effect of decreasing maternal education levels on stunting as secondary education (odd ratios $(\mathrm{OR})=1.63$; $95 \%$ confidence interval $(\mathrm{CI})=1.40-1.98)$, primary education $(\mathrm{OR}=2.95 ; 95 \%$ $\mathrm{CI}=2.51-3.46)$ and no education $(\mathrm{OR}=3.07 ; 95 \% \mathrm{CI}=2.56-3.68)$ relative to higher education. Breastfeeding for $\geqslant 12$ months was associated with a lower risk of adverse effects of primary education $(\mathrm{OR}=3.03 ; 95 \% \mathrm{CI}=1.82-3.36)$, compared to breastfeeding for $<6$ months ( $\mathrm{OR}=4.01 ; 95 \% \mathrm{CI}=1.11-15.50)$, relative to higher education. Smaller households (2-4 members) ( $\mathrm{OR}=2.96 ; 95 \% \mathrm{CI}=1.81-5.12)$ and $5-7$ ANC visits $(\mathrm{OR}=2.22 ; 95 \%$ $\mathrm{CI}=1.50-3.43)$ diminished the adverse effects of no maternal education relative to higher education on stunting.

\section{Conclusions}

In Kenya, childhood stunting still is a critical public health challenge. Parents can invest more in their offspring through planning for fewer children, attending sufficient antenatal clinics, and providing adequate breastfeeding to moderate the negative effects of low socio-economics status on their children's health.

According to United Nations Children's Fund (UNICEF), stunting, wasting and overweight combined impacted an estimated 233 million children worldwide in 2020. Additionally, about 149 million children were stunted globally in 2020 , with Africa bearing a great burden as $30.7 \%$ of African children were stunted. Furthermore, 31\% of SubSaharan African children were stunted with Eastern Africa (33\%) and Middle Africa (37\%) bearing the highest prevalence of stunting within Africa. ${ }^{1}$ However, there has been a downward trend in the number of children affected by stunting in Eastern Africa between the years 2000 (50.3 million) and 2020 (23.1 million). ${ }^{1,2}$ The Global Nutrition Report highlighted that the prevalence of stunting in Kenya in 2020 was $26 \% .^{3}$

Stunting, caused by several interlinked factors, has both short and long-term detrimental health and developmental effects on children, which include morbidity, impaired physical and cognitive development. ${ }^{4}$ The common deter- 
minants of stunting, such as food insecurity, low maternal education, inadequate water, sanitation, and hygiene, are influenced by contextual factors and how the distribution and intensity of exposures interact. ${ }^{5,6}$ Food insecurity is a common characteristic among Kenyans as half the population lives below the poverty line. ${ }^{7}$ However, maternal inability to follow recommended dietary practices, whether due to food insecurity or low health literacy, had a strong association with childhood stunting. ${ }^{8}$

The classic definitions of socioeconomic status (SES) include education level, employment, and material wealth and is conceptualised as a fundamental cause of health inequities. ${ }^{9,10}$ The education level of the mother, who is the typical caregiver to a child, is a factor repeatedly shown to influence the outcomes in stunting. ${ }^{11}$ Female empowerment through education is associated with a woman's ability to demonstrate self-agency, obtain better income, and access household resources. ${ }^{12}$ Consequently, maternal education plays a significant role in the assessment of child nutrition as higher maternal education decreases the odds of childhood stunting. ${ }^{13}$ A study in the Democratic Republic of Congo indicated a higher prevalence of stunting among children of mothers with no education (51\%) than children of mothers with higher education (13\%). ${ }^{14}$

Parental investments (PI) may be considered as additional drivers of health inequalities. PI are actions and resources taken by a parent that increase the fitness of one or more of her/his offspring and may constrain the parent's ability to invest in her/himself or future offspring. ${ }^{15}$ Previous examinations of PI in humans have been done through investment proxy measures such as parental emotional attitudes towards, as well as interactions with infants, ${ }^{16} \mathrm{di}$ rect parental care, ${ }^{17}$ and birth weight and breastfeeding. ${ }^{18}$ PI indicators in this study include current marital status as a proxy for paternal involvement, legal household size as a proxy for resource distribution, number of antenatal care (ANC) visits and duration of breastfeeding as maternal investments proxies.

Primarily, paternal involvement in the early childhood years is associated with positive physical and cognitive child development. ${ }^{19}$ Moreover, fathers are historically, and largely still today, viewed as the chief providers and protectors of their children. ${ }^{20}$ Higher rates of poor child health outcomes are correlated to polygamy. ${ }^{21}$ Apart from paternal involvement, household size is a reasonable explanation for a child's access to a nutritious diet, as household food allocation often decreases with an increase in household size. $^{22}$ Additionally, the energy and time costs of raising simultaneous children are high, and resources are finite; therefore, parents are forced to decide between the number of offspring born and the number that can be successfully reared. 23

Next, number of ANC visits is associated with favourable effects on both maternal and child health. ${ }^{24}$ Adequate ANC visits (6-10 visits) showed positive associations with stunting. ${ }^{25}$ Furthermore, breastfeeding is arguably among the most valuable forms of PI by mothers on their infants during the first 1-4 years postpartum, as it has shown to both enhance offspring survivorship, while imposing high energy requirements from the mother. ${ }^{26}$ Breastmilk consumption is associated with better cognitive development, lower in-

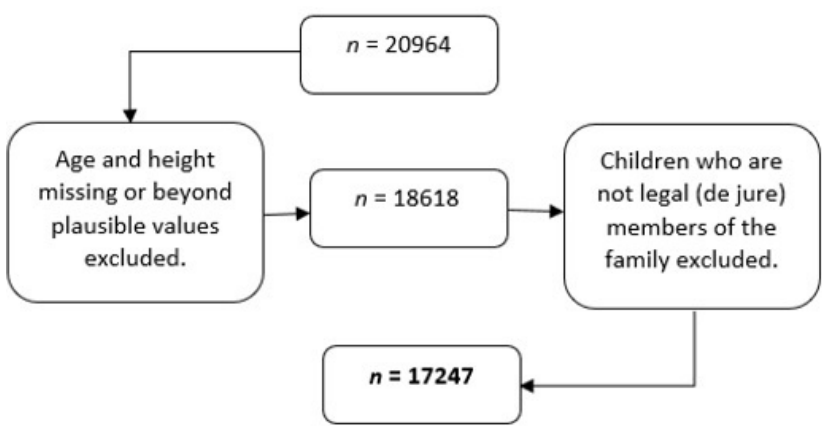

Figure 1. A sample flow chart for KDHS 2014 describing the inclusion criteria of the final sample $N=17247$.

fant morbidity, and mortality during the first five years of life. ${ }^{14,18,27}$ Although it is the mother's decision to breastfeed, World Health Organisation (WHO) recommends at least six months of exclusive breastfeeding with additional six months as complementary feeding. ${ }^{4}$

It is therefore conceivably relevant to factor in predictors that potentially represent PI in public health interventions. These PI indicators can be evaluated on how they influence child nutrition outcomes while extending knowledge on such factors. ${ }^{28}$ Despite the policy focus on reduction of stunting, there remain areas where evidence is sparse, particularly among members within low SES groups, and little is known about individual investments that parents can make towards securing the health and well-being of their children. This research utilises data, from a large Kenyan representative sample of children under 5 to investigate whether PI moderates the association between maternal education level as a proxy for socioeconomic status and stunting.

\section{METHODS}

\section{STUDY DESIGN AND SAMPLE}

This quantitative cross-sectional study design utilised a dataset obtained from Kenya Demographic and Health Survey (KDHS) conducted in 2014. The survey was implemented by the Kenya National Bureau of Statistics (KNBS) in conjunction with ICF Macro, Calverton, MD, USA. ${ }^{29}$ A representative sample of 40,300 households from 1,612 clusters spread across the country, with rural areas having 995 clusters and urban areas with 617 clusters, and 25 households were selected from each cluster. ${ }^{29}$ In total, 31,079 women aged 15-49 were eligible to be interviewed. A structured survey questionnaire was used to collect data on respondent's demographic data, SES, and maternal and childcare practices. ${ }^{29}$ Anthropometric measurements were collected from 20,964 children under five years, of which 6,829 resided in urban areas and 14,136 in rural areas. Overall, 89\% of height-for-age z-score (HFAZ) measurements were valid. Children who: were not legal members of the household, had height and age values that were missing or not plausible were excluded. The analysis included 17247 children selected through a criterion shown in Figure 1. 


\section{VARIABLES}

The independent variable, maternal education, as a proxy for SES was measured as four subgroups (no education, primary education, secondary education and higher). Additionally, the WHO defines stunting as a child's failure to reach linear growth potential characterised by HFAZ that is below minus two standard deviations (SD) below the WHO growth standards median for children at his/her age. ${ }^{5}$ HFAZ was analysed as stunted (<-2SD) or not stunted (>-2SD). Next, PI was indicated by marital status as a paternal involvement proxy measured as three subgroups (widowed, never in union/divorced/separated, and married/cohabiting); distribution of household resources measured by the number of legal household members (2-4 members, 5-6 members and $\geqslant 7$ members); maternal involvement measured by the number of ANC visits ( $<4$ visits, $4-7$ visits and $\geqslant 8$ visits), and breastfeeding duration ( $<6$ months, $6-11$ months, $\geqslant 12$ months). Additionally, background factors: residence (urban vs rural), sex of the child (male vs female) and age of the child in months were treated as potential confounders.

\section{STATISTICAL ANALYSIS}

IBM SPSS statistics version 27 (SPSS Inc., Chicago IL, USA) was used for all calculations of stunting and its explanatory variables. First, missing data analysis was conducted to understand whether the missing values of ANC visits and breastfeeding duration were random or not. Breastfeeding duration had $52 \%$ of missing data. Breastfeeding duration missing value rate was comparable across education level, household size, number of ANC visits and marital status (PI indicators), as shown in Table $S 1$ in the Online Supplementary Document. Additionally, Table $S 2$ in the Online Supplementary Document highlights the Little's Missing Completely at Random (MCAR) test's $P=0.087$ indicating MCAR, as the probability of an observation being missing depended on neither observed nor unobserved data. ${ }^{30}$ Breastfeeding duration, as such, was a vital variable of interest and had no indication of possible systematic bias based on being MCAR, and as such, was analysed without imputation. ${ }^{31}$ Although $23 \%$ of data on the number of ANC visits was missing, Little MCAR test's $P<0.001$; thus not MCAR, and the missing value rate was not comparable across education level, and PI variables strata indicating that the missing data was Missing at Random (MAR) as the probability of an observation being missing depended only on the observed data, see Table S3 in the Online Supplementary Document. There were systematic differences in missing ANC values explained by other explanatory variables and may generate a potential for systematic bias. However, it was difficult to determine if the number of ANC visits was Missing Not at Random (MNAR) because of the unlikelihood to ascertain if the probability of these missing values also depended on some unobserved data or on the actual values of the number of ANC visits, which are missing hence unknown in the first place. Since we could not, beyond a reasonable doubt, confirm that number of ANC visits data is only MAR and not MNAR, it was analysed without imputations due to the large dataset, and multiple im-

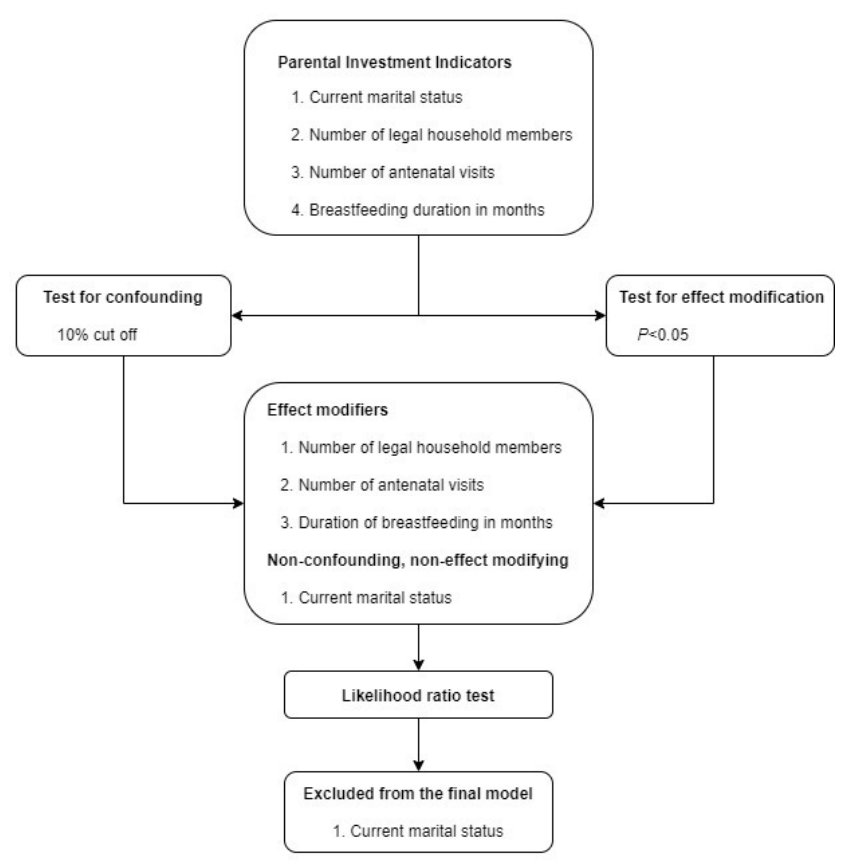

Figure 2. The conceptual framework of the statistical analysis of the sample describing the statistical decision-making process.

putations would introduce potential sources of bias. ${ }^{32}$

For the main analysis, frequency tables and cross-tabulations were used to establish the frequency distribution of variables and prevalence of stunting. To establish causality between maternal education, PI and stunting, PI variables were first tested for confounding using a $10 \%$ cut off on percentage change in OR, see Figure 2. Additionally, it was important to test for moderation (effect modifier) by examining whether PI variables changed the magnitude of the effects of decreasing maternal education on stunting depending on the PI variable stratum. Since all the variables of interest are dichotomous, interactions between maternal education level and selected PI variables were based on the product terms of the main exposure variable and the potential moderator. Estimates with $P<0.05$ were interpreted as having interaction effects between maternal education level and PI indicator of interest on stunting.

Finally, after establishing a "best fit model”, logistic regressions were used to calculate crude OR, adjusted OR and stratified OR to estimate the risk of stunting related to maternal education, adjusted for age, sex and type of residence, and stratified by PI. An adjustment was made for the unequal sampling probabilities using the sample weights provided in the KDHS dataset by including final weights in all statistical models.

\section{ETHICS CONSIDERATIONS}

The Institutional Review Board (IRB) of ICF International reviewed and approved The Demographic and Health Surveys-7 (DHS-7). The 2014 KDHS is categorised under that approval. The IRB of ICF International complied with the United States Department of Health and Human Services requirements for the "Protection of Human Subjects" (ICF 
International is now known as ICF). Informed consent statements were read to respondents, who either accepted or declined to participate, before and during each interview. Parents and guardians provided consent prior to the child or adolescent participation. The data was obtained free of charge from KDHS by submitting a research proposal with a request to access the most recent national data. The unidentified KDHS 2014 data, as defined in the latest issue of the Declaration of Helsinki - Ethical Principles for Medical Research Involving Human Subjects developed by the World Medical Association, was only used for the purpose of statistical analysis and reporting of this research.

\section{RESULTS}

The definitive sample constituted of 17247 children under age 5 , with an almost equal distribution between females and males. The mean HFAZ was -113.76 with a standard deviation of 140.22, as displayed in Table 1. Further, 26\% of children were stunted, more among males (30\%) than females $(22 \%)$. The prevalence of stunting was higher in rural (30\%) than urban areas (20\%). Children aged 12-35 months had the highest prevalence of stunting (35\%). The least stunted children fell in the richest wealth index (13\%) and highest education level (13\%). Additionally, the prevalence of stunting was highest among children whose mothers attended <4 ANC visits (28\%) and children from households with $\geqslant 7$ members (30\%).

Table 2 indicates the interaction effects between education level and household size; education level and the number of ANC visits; and education level and duration of breastfeeding (all $P<0.001$ ). The $\mathrm{R}^{2}$ values of these interactions indicate that the separate interactions of education level and marital status, household size, number of ANC visits, and breastfeeding duration respectively explained $3 \%$ $(P<0.001), 3 \%(P<0.001), 3 \%(P<0.001)$, and 5\% $(P<0.001)$, of the variations in the outcomes of stunting respectively. The further analysis shown in Table 3 indicates that maternal education had a positive association with stunting; secondary education compared to higher education had the least odds of stunting $(\mathrm{OR}=1.63$; 95\% $\mathrm{CI}=1.40-1.98)$, and no education compared to higher education had the highest odds (OR=3.07; 95\% CI=2.56-3.68). A similar trend was observed in the multivariable adjusted models (all $P<0.001$ ).

The stratified analysis, shown in Table 3 , illustrates the adverse effect of decreasing the education levels despite the household size. Small households (2-4 members) were protective as they presented a lower risk of adverse effects of no education level $(\mathrm{OR}=2.96$; $95 \% \mathrm{CI}=1.81-5.12)$ on stunting compared to primary education level (OR=3.40; $95 \%$ $\mathrm{CI}=2.42-5.27)$. For the medium-sized households (5-6 members), lower maternal education posed a greater risk to childhood stunting; no education (OR=3.07; 95\% $\mathrm{CI}=1.76-5.69)$ and primary education (OR=2.44; 95\% $\mathrm{CI}=1.49-4.36)$ relative to higher education. There was little evidence of an effect of education in the largest household category, but the largest households were associated with the lowest odds of stunting (all $P>0.05$ ).

Additionally, stratified results for ANC visits demonstrated that reduced education level posed a greater risk of childhood stunting, relative to higher education, among all
ANC categories. The 5-7 ANC visits group was associated with lower a risk of adverse effects of decreasing maternal education among no education level $(\mathrm{OR}=2.22$; 95\% $\mathrm{CI}=1.50-3.43)$ compared to primary education $(\mathrm{OR}=2.45$; $95 \% \mathrm{CI}=1.85-3.48)$. Also, $\geqslant 8$ ANC visits category was associated with the highest odds of stunting relative to higher education, despite the group's association with lower risk of adverse effects of no education (OR=6.35; 95\% $\mathrm{CI}=0.58-69.78)$ compared to primary education $(\mathrm{OR}=12.86$; 95\% CI=2.11-47.35).

Next, there was an increasing linear trend in odds of stunting with decreasing maternal education levels in both $<6$ months and $\geqslant 12$ months of breastfeeding groups. In general, breastfeeding for $<6$ months was associated with the highest odds of stunting in no education $(\mathrm{OR}=4.01 ; 95 \%$ $\mathrm{CI}=0.96-16.55)$, primary $(\mathrm{OR}=4.01 ; 95 \% \mathrm{CI}=1.11-15.50)$, and secondary $(\mathrm{OR}=3.78 ; 95 \% \mathrm{CI}=0.88-13.36 ; P=0.055)$ relative to higher education levels. Generally, breastfeeding for $\geqslant 12$ months was associated with a lower risk of adverse effects of secondary $(\mathrm{OR}=1.74 ; 95 \% \mathrm{CI}=1.18-2.26)$, primary $(\mathrm{OR}=3.03$; 95\% $\mathrm{CI}=1.82-3.36)$ and no education (OR=3.47; 95\% $\mathrm{CI}=1.98-4.11)$ compared to breastfeeding for $<6$ months, relative to higher education.

\section{DISCUSSION}

The results from this cross-sectional study indicated a positive association between maternal education level and childhood stunting in Kenya. This association was moderated by household size, the number of ANC visits and breastfeeding duration. Furthermore, related to societal arrangements of power and property, the health of a population is frequently affiliated with the SES of the people within the population. ${ }^{33,34}$ This study corresponded with evidence from Malawi, Tanzania and Zimbabwe, indicating that a higher level of maternal education level is advantageous in achieving better health outcomes among children. 35

Like the low- and middle-income countries (LMICs) average, $26 \%$ of children in this sample were stunted..$^{3}$ The prevalence was higher among male (30\%) than female (22\%) children. This tendency coincides with a systematic review and research studies that highlighted that female children are less likely to be stunted than their male counterparts. ${ }^{17,36,37}$ Moreover, these findings were consistent with the suggestion that the reproductive prospect of a child is directly correlated with PI, and fertility prospects are higher in female than male children translating to more PI in females. ${ }^{18}$ Additionally, males generally have higher daily caloric needs than females. ${ }^{38}$

This study further emphasised that urban areas experienced a lower prevalence of stunting (20\%) than rural areas (29\%). A possible explanation for these findings could be that modernisation through the introduction of interventions in health, economy, and society may reduce extrinsic environmental risks to poor health. 39

Fathers often provide for and protect their children and have shown to be involved both prenatally and postnatally by assisting their partners regardless of marital status. ${ }^{19,20}$ However, this study did not clearly show child nutritional status benefits from being in a partnership as the preva- 
Table 1. Stunting prevalence among 17247 children under 5 years (Kenya, 2014)

\begin{tabular}{|c|c|c|c|c|}
\hline Variables & Frequency & Mean \pm SD & Frequency \% & Stunted \% \\
\hline Stunted & 4459 & $-113.76 \pm 140.22$ & 26 & - \\
\hline \multicolumn{5}{|c|}{ Maternal Education Level $(N=17248)$} \\
\hline Higher & 1435 & - & 8 & 13 \\
\hline Secondary & 4038 & - & 23 & 19 \\
\hline Primary & 9718 & - & 56 & 30 \\
\hline No education & 2057 & - & 12 & 31 \\
\hline \multicolumn{5}{|l|}{ Wealth Index ( $N=17248)$} \\
\hline Richest & 3330 & - & 19 & 13 \\
\hline Richer & 2952 & - & 17 & 21 \\
\hline Middle & 3176 & - & 18 & 25 \\
\hline Poorer & 3616 & - & 21 & 30 \\
\hline Poorest & 4173 & - & 24 & 36 \\
\hline \multicolumn{5}{|l|}{$\operatorname{Sex}(N=17246)$} \\
\hline Female & 8504 & - & 49 & 22 \\
\hline Male & 8742 & - & 51 & 30 \\
\hline Age $(N=17248)$ & & $29.09 \pm 17.01$ & & \\
\hline $0-12$ months & 3081 & - & 20 & 13 \\
\hline $12-23$ months & 3194 & - & 21 & 31 \\
\hline 24-35 months & 3161 & - & 21 & 35 \\
\hline $36-47$ months & 3089 & - & 20 & 29 \\
\hline 48-59 months & 2887 & - & 19 & 23 \\
\hline \multicolumn{2}{|c|}{ Number of legal household members $(N=17246)$} & $5.78 \pm 2.42$ & & \\
\hline$\geq 7$ members & 3565 & - & 32 & 30 \\
\hline 5-6 members & 7614 & - & 33 & 25 \\
\hline 2-4 members & 6068 & - & 35 & 23 \\
\hline \multicolumn{5}{|c|}{ Paternal Investment Proxy (N=17248) } \\
\hline Married/Living with partner & 14727 & - & 85 & 26 \\
\hline Divorced/Separated/Unmarried & 2168 & - & 13 & 26 \\
\hline Widowed & 353 & - & 2 & 30 \\
\hline ANC visits $(N=12955)$ & & $3.97 \pm 1.87$ & & \\
\hline$<4$ visits & 5448 & - & 42 & 28 \\
\hline 4-7 visits & 7038 & - & 54 & 22 \\
\hline$\geq 8$ visits & 506 & - & 4 & 16 \\
\hline \multicolumn{2}{|c|}{ Breast feeding duration in months $(N=8246)$} & $15.88 \pm 8.23$ & & \\
\hline$<6$ months & 956 & - & 11 & 12 \\
\hline 6-11 months & 1518 & - & 28 & 23 \\
\hline$\geq 12$ months & 5819 & - & 62 & 30 \\
\hline \multicolumn{5}{|l|}{ Settlement $(N=17247)$} \\
\hline Rural & 11331 & - & 66 & 29 \\
\hline Urban & 5916 & - & 34 & 20 \\
\hline
\end{tabular}

Note. SD: Standard deviation

Higher education: College and university education; ANC: Antenatal care.

All percentages (\%) are rounded off to the nearest whole number.

lence of stunting was $26 \%$ whether the children's parents were in a partnership or not.

This study showed relative benefits of 5-7 ANC visits in lowering the adverse effects of no education on stunting compared to $\leqslant 4$ ANC visits. Similarly, a study in Honduras established a positive association between stunting and ANC visits between 6-10 visits. ${ }^{17}$ Moreover, WHO recommends a minimum of 8 ANC visits for improved post-natal 
Table 2. Interaction effects between maternal education and PI on stunting (Kenya, 2014)

\begin{tabular}{|c|c|c|}
\hline Interacting variables & $\begin{array}{l}\text { Interaction OR }(95 \% \mathrm{CI}) \\
P \text {-value }\end{array}$ & $\begin{array}{l}\text { Adjusted } \mathbf{R}^{2} \\
P \text {-value }\end{array}$ \\
\hline Maternal education *marital status & $\begin{array}{l}0.96(0.91-1.02) \\
0.091\end{array}$ & $\begin{array}{l}0.031 \\
<0.001\end{array}$ \\
\hline Maternal education * household size & $\begin{array}{l}0.918(0.89-0.95) \\
<0.001\end{array}$ & $\begin{array}{l}0.032 \\
<0.001\end{array}$ \\
\hline Maternal education * number of ANC visits & $\begin{array}{l}0.84(0.81-0.89) \\
<0.001\end{array}$ & $\begin{array}{l}0.033 \\
<0.001\end{array}$ \\
\hline Maternal education * duration of breastfeeding & $\begin{array}{l}1.42(1.33-1.51) \\
<0.001\end{array}$ & $\begin{array}{l}0.053 \\
<0.001\end{array}$ \\
\hline
\end{tabular}

Note. OR: Odds ratio; $\mathrm{R}^{2}$ : The proportion of variance for a dependent variable explained by education level

PI: Parental investment; ANC: Antenatal care.

outcomes. ${ }^{40}$ However, this study highlighted that $\geqslant 8$ ANC visits generally had higher odds of stunting, with decreasing levels of maternal education. The evidence from this study does not align with the WHO guidelines, but this might be explained by other factors that have not been considered in this study such as chronic maternal illnesses. Moreover, there are some potential systematic biases that may have arisen from missing values within the ANC variables, and such biases could potentially explain these results.

One study suggested that children from lower SES households could have better nutrition outcomes if sufficiently breastfed due to the interaction between SES and breastfeeding. ${ }^{41}$ This corresponds with our finding that breastfeeding for $\geqslant 12$ months indicated lower odds of stunting among the two lowest education levels compared to breastfeeding for $<6$ months. These results correlated with the WHO's recommendation for infants to be exclusively breastfed for at least six months with additional six months as complementary feeding. ${ }^{4}$ Proponents of better nutrition outcomes in children have also suggested promising interventions that include promotion of breastfeeding and appropriate complementary feeding of children, among others. ${ }^{42}$

Traditional life history assumes that PI trade-offs are often determined by the number of children in a household, with older children experiencing higher investments which reduce with each additional increase in birth order. ${ }^{41,43}$ Comparably, this study indicated that larger households had the highest prevalence of stunting (30\%). This corresponded with a study that highlighted that children who belonged to large households of 8 and more members were most stunted. ${ }^{44}$ Also, smaller households were associated with lower odds of stunting $(\mathrm{OR}=2.96$; 95\% CI=1.81-5.12) at the lowest education level compared to medium households $(\mathrm{OR}=3.07 ; 95 \% \mathrm{CI}=1.76-5.69)$. These results assumed the explanation that household food allocation decreased with an increase in household size, and when resources are limited, parents make decisions on how to invest within the household. ${ }^{13,45}$ However, large households were associated with the lowest odds of adverse effects of stunting related to decreased maternal education levels (all $P>0.05$ ). A likely explanation for this finding is that older siblings could exert a positive influence through participating in childcare provision of the younger children hence better child health outcomes. ${ }^{22,23}$

\section{STRENGTHS AND LIMITATIONS}

This research utilises extensive representative national data. However, the selection process of the PI markers was based on a limited number of markers, and residual confounding may be present. Breastfeeding duration was examined as to any type of breastfeeding, and this study did not explore whether it was exclusive or not. Finally, the number of ANC visits had a substantial amount of missing data that could not be clearly established as either MAR or MNAR and hence was not imputed as both not imputing and imputing were potential sources of bias.

\section{CONCLUSIONS}

The study examined whether PI through paternal involvement, household size, number of ANC visits, and breastfeeding duration moderated the effect of maternal education on childhood stunting. We found that household size, number of ANC visits and breastfeeding duration moderated the effect of maternal education level on stunting. In this study, children at greatest risk of stunting were children that received inadequate breastfeeding of fewer than six months. Using a representative national sample, this research demonstrated that parental investments such as adequate breastfeeding ( $\geqslant 12$ months), having smaller households (2-4 members), and 4-7 ANC visits weakened the adverse effects of decreasing levels of education on childhood stunting. Parental investments can moderate the adverse effects of lower socio-economic status on a children's health; therefore, future studies should integrate more diverse sets of parental investment indicators with health outcomes among children and further indicate how policies may be most effective at promoting advantageous parental behaviours, especially for households in lower socio-economic levels. 
Table 3. Maternal education and stunting: crude and adjusted associations, stratified by household size, number of ANC visits and breastfeeding duration

\begin{tabular}{|c|c|c|c|c|c|}
\hline Model 1 & Crude & Adjusted* & $\begin{array}{l}\text { Household size } \\
\text { members }\end{array}$ & & \\
\hline $\begin{array}{l}\text { Education } \\
\text { level }\end{array}$ & $\begin{array}{l}\text { OR }(95 \% \mathrm{CI}) \\
P \text {-value }\end{array}$ & $\begin{array}{l}\text { OR }(95 \% \mathrm{Cl}) \\
P \text {-value }\end{array}$ & 2-4 members & 5-6 members & $\geq 7$ members \\
\hline Higher & Ref & Ref & Ref & Ref & Ref \\
\hline Secondary & $\begin{array}{l}1.63(1.40-1.98) \\
<0.001\end{array}$ & $\begin{array}{l}1.49(1.21-2.15) \\
0.001\end{array}$ & $\begin{array}{l}1.99(1.43-3.21) \\
0.001\end{array}$ & $\begin{array}{l}1.27 \\
(0.77-2.39) \\
0.450\end{array}$ & $\begin{array}{l}0.75(0.37-1.38) \\
0.334\end{array}$ \\
\hline Primary & $\begin{array}{l}2.95(2.51-3.46) \\
<0.001\end{array}$ & $\begin{array}{l}2.48(1.99-3.43) \\
<0.001\end{array}$ & $\begin{array}{l}3.40(2.42-5.27) \\
<0.001\end{array}$ & $\begin{array}{l}2.44 \\
(1.49-4.36) \\
0.003\end{array}$ & $\begin{array}{l}1.17(0.50-1.68) \\
0.573\end{array}$ \\
\hline $\begin{array}{l}\text { No } \\
\text { Education }\end{array}$ & $\begin{array}{l}3.07(2.56-3.68) \\
<0.001\end{array}$ & $\begin{array}{l}2.59(1.98-3.75) \\
<0.001\end{array}$ & $\begin{array}{l}2.96(1.81-5.12) \\
<0.001\end{array}$ & $\begin{array}{l}3.07 \\
(1.76-5.69) \\
0.001\end{array}$ & $\begin{array}{l}1.18(0.43-1.62) \\
0.599\end{array}$ \\
\hline \multirow[t]{2}{*}{ Model 2} & & & \multicolumn{3}{|c|}{ Antenatal clinic visits } \\
\hline & & & $<4$ visits & $4-7$ visits & $\geq 8$ visits \\
\hline Higher & Ref & Ref & Ref & Ref & Ref \\
\hline Secondary & $\begin{array}{l}1.63(1.40-1.98) \\
<0.001\end{array}$ & $\begin{array}{l}1.45(1.23-2.03) \\
0.005\end{array}$ & $\begin{array}{l}1.51(0.87-3.05) \\
0.211\end{array}$ & $\begin{array}{l}1.33 \\
(1.01-1.98) \\
0.102\end{array}$ & $\begin{array}{l}4.16 \\
(0.77-21.01) \\
0.096\end{array}$ \\
\hline Primary & $\begin{array}{l}2.95(2.51-3.46) \\
<0.001\end{array}$ & $\begin{array}{l}2.58(2.19-3.54) \\
<0.001\end{array}$ & $\begin{array}{l}2.17(1.23-4.17) \\
0.015\end{array}$ & $\begin{array}{l}2.45 \\
(1.85-3.48) \\
<0.001\end{array}$ & $\begin{array}{l}12.86 \\
(2.11-47.35) \\
0.002\end{array}$ \\
\hline $\begin{array}{l}\text { No } \\
\text { Education }\end{array}$ & $\begin{array}{l}3.07(2.56-3.68) \\
<0.001\end{array}$ & $\begin{array}{l}2.49(2.06-3.55) \\
<0.001\end{array}$ & $\begin{array}{l}2.51(1.37-4.97) \\
0.006\end{array}$ & $\begin{array}{l}2.22 \\
(1.50-3.43) \\
<0.001\end{array}$ & $\begin{array}{l}6.35 \\
(0.58-69.78) \\
0.070\end{array}$ \\
\hline \multirow[t]{2}{*}{ Model 3} & & & \multicolumn{3}{|c|}{ Breastfeeding duration in months } \\
\hline & & & $<6$ months & 6-11 months & $\geq 12$ months \\
\hline Higher & Ref & Ref & Ref & Ref & Ref \\
\hline Secondary & $\begin{array}{l}1.63(1.40-1.98) \\
<0.001\end{array}$ & $\begin{array}{l}1.57(1.37-2.02) \\
<0.001\end{array}$ & $\begin{array}{l}3.78(0.88-13.36) \\
0.055\end{array}$ & $\begin{array}{l}0.85 \\
(0.48-2.20) \\
0.574\end{array}$ & $\begin{array}{l}1.74(1.18-2.26) \\
0.003\end{array}$ \\
\hline Primary & $\begin{array}{l}2.95(2.51-3.46) \\
<0.001\end{array}$ & $\begin{array}{l}2.47(2.22-3.21) \\
<0.001\end{array}$ & $\begin{array}{l}4.01(1.11-15.50) \\
0.034\end{array}$ & $\begin{array}{l}3.03 \\
(1.50-6.14) \\
0.002\end{array}$ & $\begin{array}{l}3.03(1.82-3.36) \\
<0.001\end{array}$ \\
\hline $\begin{array}{l}\text { No } \\
\text { Education }\end{array}$ & $\begin{array}{l}3.07(2.56-3.68) \\
<0.001\end{array}$ & $\begin{array}{l}3.05(2.46-3.78) \\
<0.001\end{array}$ & $\begin{array}{l}4.01(0.96-16.55) \\
0.060\end{array}$ & $\begin{array}{l}1.13 \\
(0.75-3.91) \\
0.691\end{array}$ & $\begin{array}{l}3.47(1.98-4.11) \\
<0.001\end{array}$ \\
\hline
\end{tabular}

*Model 1: Stratified by household size and adjusted for adjusted for age, sex, type of residence, number of ANC visits and breastfeeding duration. Model 2: Stratified by number of ANC visits and adjusted for age, sex, type of residence, household size and breastfeeding.

Model 3: Stratified by breastfeeding duration and adjusted for age, sex, type of residence, household size and number of ANC visits.

OR: Odds ratio; Ref: reference category ( $\mathrm{OR}=1)$; $\mathrm{CI}$ : Confident interval; Higher education: College and university education; ANC: Antenatal care.

\section{ACKNOWLEDGEMENTS}

The authors would like to thank Catrine Wessman from School of Public Health \& Community Medicine, University of Gothenburg, Sweden for the statistical consult

\section{FUNDING}

None

\section{AUTHORSHIP CONTRIBUTIONS}

VM formulated the research aim, reviewed literature, analysed and synthesised the data, and prepared the man- uscript; LL and MH supervised the study's conceptualisation, data synthesis and interpretation and commented on the manuscript at all stages including final approval.

\section{COMPETING INTERESTS}

The authors completed the Unified Competing Interest form at http://www.icmje.org/disclosure-of-interest/ (available upon request from the corresponding author), and declare no conflicts of interest.

\section{CORRESPONDENCE TO:}

Monica Hunsberger PhD, 
School of Public Health \& Community Medicine, Institute of Medicine, Sahlgrenska Academy, University of Gothenburg, Box 100, 40530 Gothenburg, Sweden.

monica.hunsberger@gu.s
Submitted: August 23, 2021 GMT, Accepted: September 24, 2021 GMT 


\section{REFERENCES}

1. United Nations Children's Fund (UNICEF) WHO, International Bank for Reconstruction and Development/The World Bank. Levels and Trends in Child Malnutrition: Key Findings of the 2020 Edition of the Joint Child Malnutrition Estimates. World Health Organization Accessed September 29, 2021. https://w ww.who.int/news/item/31-03-2020-unicef-who-wb-j me-group-new-data

2. UNICEF. Levels and trends in child malnutrition UNICEF-WHO-World Bank Group joint child malnutrition estimates: key findings of the 2019 edition. Accessed September 29, 2021. https://www.w ho.int/nutgrowthdb/ime-2019-key-findings.pdf

3. Global Nutrition Report. The burden of malnutrition at a glance. Accessed September 29, 2021. https://globalnutritionreport.org/resources/nut rition-profiles/africa/eastern-africa/kenya/

4. WHO, UNICEF. WHO child growth standards and the identification of severe acute malnutrition in infants and children: joint statement by the World Health Organization and the United Nations Children's Fund. Accessed September 29, 2021. http s://apps.who.int/iris/bitstream/handle/10665/44129/9 789241598163 eng.pdf

5. De Onis M, Branca F. Childhood stunting: a global perspective. Maternal \& Child Nutrition. 2016;12:12-26. doi:10.1111/mcn.12231

6. Sunuwar DR, Singh DR, Pradhan PMS. Prevalence and factors associated with double and triple burden of malnutrition among mothers and children in Nepal: evidence from 2016 Nepal demographic and health survey. BMC Public Health. 2020;20(1). doi:10.1 186/s12889-020-8356-y

7. Loewenberg S. Breaking the cycle: drought and hunger in Kenya. The Lancet. 2014;383(9922):1025-1028. doi:10.1016/s0140-6736(1 4)60492-x

8. Debela BL, Demmler KM, Rischke R, Oaim M. Maternal nutrition knowledge and child nutritional outcomes in urban Kenya. Appetite.

2017;116:518-526. doi:10.1016/i.appet.2017.05.042

9. Kleinman A. Four social theories for global health. The Lancet. 2010;375(9725):1518-1519. doi:10.1016/s $\underline{0140-6736(10) 60646-0}$

10. Berkman LF, Kawachi I, Glymour MM. Social Epidemiology. Second edition. Oxford University Press; 2014. doi:10.1093/med/9780195377903.001.00 $\underline{01}$
11. Biemba G. P4.1510VC Status as Predictor of Poor Outcomes in Children; Combination of Household Poverty and Caring for OVC Has Worse Child Outcomes. Sexually Transmitted Infections. 2013;89(Suppl 1):A334.2-A334. doi:10.1136/sextran $\underline{\text { s-2013-051184.1046 }}$

12. Omwami EM. Intergenerational comparison of education attainment and implications for empowerment of women in rural Kenya. Gender, Place \& Culture. 2015;22(8):1106-1123. doi:10.1080/096636 9x.2014.939152

13. Rahman M. Association between order of birth and chronic malnutrition of children: a study of nationally representative Bangladeshi sample. Cadernos de Saúde Pública. 2016;32(2). doi:10.1590/01 $\underline{02-311 \times 00011215}$

14. Kismul H, Acharya P, Mapatano MA, Hatløy A. Determinants of childhood stunting in the Democratic Republic of Congo: further analysis of Demographic and Health Survey 2013-14. BMC Public Health. 2018;18(1). doi:10.1186/s12889-017-4621-0

15. Clutton-Brock TH. The Evolution of Parental Care. Princeton University Press; 1991. doi:10.1515/978069 1206981

16. Hagen EH. The Functions of Postpartum Depression. Evolution and Human Behavior. 1999;20(5):325-359. doi:10.1016/s1090-5138(99)0001 $\underline{6-1}$

17. Sparks CS. Parental investment and socioeconomic status influences on children's height in Honduras: An analysis of national data. American Journal of Human Biology. 2011;23(1):80-88. doi:10.10 02/ajhb.21104

18. Tracer DP. Breastfeeding structure as a test of parental investment theory in Papua New Guinea. American Journal of Human Biology. 2009;21(5):635-642. doi:10.1002/ajhb.20928

19. Teitler JO. Father involvement, child health and maternal health behaviour. Children and Youth Services Review. 2001;23(4):403-425. doi:10.1016/s019 0-7409(01)00137-2

20. Rosenberg J. The Importance of Fathers in the Healthy Development of Children. US Department Health and Human Services, Administration for Children and; 2006. https://doi.org/10.1037/e6244520 07-001 
21. Strassmann BI. Polygyny as a Risk Factor for Child Mortality among the Dogon. Current Anthropology. 1997;38(4):688-695. doi:10.1086/204657

22. Hagen EH, Barrett HC, Price ME. Do human parents face a quantity-quality trade-off?: Evidence from a Shuar community. American Journal of Physical Anthropology. 2006;130(3):405-418. doi:10.1002/ajp a.20272

23. Lawson DW, Mace R. Parental investment and the optimisation of human family size. Philosophical Transactions of the Royal Society B: Biological Sciences. 2011;366(1563):333-343. doi:10.1098/rstb.2010.0297

24. Noonan K, Corman H, Schwartz-Soicher O, Reichman NE. Effects of Prenatal Care on Child Health at Age 5. Maternal and Child Health Journal. 2013;17(2):189-199. doi:10.1007/s10995-012-0966-2

25. Khan S, Zaheer S, Safdar NF. Determinants of stunting, underweight and wasting among children < 5 years of age: evidence from 2012-2013 Pakistan demographic and health survey. BMC Public Health. 2019;19(1). doi:10.1186/s12889-019-6688-2

26. Prentice AM. The Double Burden of Malnutrition in Countries Passing through the Economic Transition. Annals of Nutrition and Metabolism. 2018;72(Suppl. 3):47-54. doi:10.1159/000487383

27. Medhin G, Hanlon C, Dewey M, et al. Prevalence and predictors of undernutrition among infants aged six and twelve months in Butajira, Ethiopia: The PMaMiE Birth Cohort. BMC Public Health. 2010;10(1):27. doi:10.1186/1471-2458-10-27

28. Smith L, Haddad L. Reducing Child Undernutrition: Past Drivers and Priorities for the Post-MDG Era. IDS Working Papers. 2014;2014(441):1-47. doi:10.1111/i.2040-0209.2014.0 0441.x

29. KDHS. Kenya Demographic and Health Survey. Kenya National Bureau of Statistics Accessed September 29, 2021. https://dhsprogram.com/pubs/p df/FR308/FR308.pdf

30. Sterne JA, White IR, Carlin JB, et al. Multiple imputation for missing data in epidemiological and clinical research: potential and pitfalls. $B M J$. 2009;338. doi:10.1136/bmj.b2393

31. Jakobsen JC, Gluud C, Wetterslev J, Winkel P. When and how should multiple imputation be used for handling missing data in randomised clinical trials - a practical guide with flowcharts. BMC Medical Research Methodology. 2017;17(1). doi:10.1186/s1287 4-017-0442-1
32. Bhaskaran K, Smeeth L. What is the difference between missing completely at random and missing at random? International Journal of Epidemiology. 2014;43(4):1336-1339. doi:10.1093/ije/dyu080

33. Krieger N. Embodiment: a conceptual glossary for epidemiology. Journal of Epidemiology \& Community Health. 2005;59(5):350-355. doi:10.1136/jech.2004.02 4562

34. Krieger N. Ecosocial Theory of Disease Distribution: Embodying Societal \& Ecologic Context. Oxford University Press; 2011. doi:10.1093/acprof:oso/97801 95383874.003.0007

35. Makoka D, Masibo PK. Is there a threshold level of maternal education sufficient to reduce child undernutrition? Evidence from Malawi, Tanzania and Zimbabwe. BMC Paediatrics. 2015;15(1). doi:10.1186/s 12887-015-0406-8

36. Marston C, Cleland J. Do unintended pregnancies carried to term lead to adverse outcomes for mother and child? An assessment in five developing countries. Population Studies. 2003;57(1):77-93. doi:1 $\underline{0.1080 / 0032472032000061749}$

37. Nshimyiryo A, Hedt-Gauthier B, Mutaganzwa C, et al. Risk factors for stunting among children under five years: a cross-sectional population-based study in Rwanda using the 2015 Demographic and Health Survey. BMC Public Health. 2019;19(1). doi:10.1186/s1 2889-019-6504-Z

38. Torun B. Energy requirements of children and adolescents. Public Health Nutrition.

2005;8(7a):968-993. doi:10.1079/phn2005791

39. Gibson MA, Lawson DW. "Modernisation" increases parental investment and sibling resource competition: evidence from a rural development initiative in Ethiopia. Evolution and Human Behaviour. 2011;32(2):97-105. doi:10.1016/i.evolhumbehav.201 $\underline{0.10 .002}$

40. WHO. WHO recommendations on antenatal care for a positive pregnancy experience: Summary. Accessed September 29, 2021. https://apps.who.int/iri s/bitstream/handle/10665/259947/WHO-RHR-18.02-e ng.pdf?sequence $=1$

41. Howell EM, Holla N, Waidmann T. Being the younger child in a large African Family: a study of birth order as a risk factor for poor health using the demographic and health surveys for 18 countries. BMC Nutrition. 2016;2(1). doi:10.1186/s40795-016-01 $\underline{00-8}$ 
42. Black RE, Victora CG, Walker SP, et al. Maternal and child undernutrition and overweight in lowincome and middle-income countries. The Lancet. 2013;382(9890):427-451. doi:10.1016/s0140-6736(1 3)60937-x

43. Hauser RM, Blake J. Family Size and Achievement. Population and Development Review. 1989;15(3):561. oi:10.2307/1972447
44. Bogale TY, Bala ET, Tadesse M, Asamoah BO. Prevalence and associated factors for stunting among 6-12 years old school age children from rural community of Humbo district, Southern Ethiopia. BMC Public Health. 2018;18(1). doi:10.1186/s12889-0 18-5561-z

45. Lack D. The Significance of Clutch-size. Ibis. 2008;89(2):302-352. doi:10.1111/j.1474-919x.1947.tb $\underline{04155 . \mathrm{x}}$ 


\section{SUPPLEMENTARY MATERIALS}

\section{Online Supplementary Document}

Download: https://www.joghr.org/article/29462-parental-investment-can-moderate-the-negative-effects-of-lowsocioeconomic-status-on-children-s-health-an-analysis-of-kenyan-national-data/attachment/74232.docx 